\title{
The Metaphysics of Logical Atomism
}

\author{
Bernard Linsky \\ May 12, 2000
}

Bertrand Russell made use of logic as an analytical tool from the start of his philosophical career and early on adopted a metaphysics that can be called "atomism" in opposition to "monism". The name "Logical Atomism" is nevertheless useful for identifying a distinctive combination of metaphysical and logical doctrines characteristic of Russell's work from around 1910 to at least 1925. Russell introduced the name in his series of lectures in 1918 [PLA], so characterising his "philosophical position" and used it again later for the title of a 1924 essay [LA]. He describes this philosophy as the combination of a "...logical doctrine which seems to me to result from the philosophy of mathematics..." and "...on the basis of this a certain kind of metaphysic.” (PLA, 160). The metaphysics is not simply derivative from his logical theory resulting merely from reading a metaphysical theory off the expressions of a logically perspicuous language. In a passage of the lectures on the notion of complexity Russell describes certain definitions as "...preliminary because they start from the complexity of the proposition, which we define psychologically, and proceed to the complexity of the fact, whereas it is quite clear that in an orderly, proper procedure it is the complexity of the fact that you would start from." (PLA, 175). The right way to analyze certain expressions into a logical language would seem to follow 
from a correct metaphysical analysis of facts rather than leading it. In the lectures the project is described in a very world-oriented way:

I think one might describe philosophical logic, the philosophical portion of logic which is the portion that I am concerned with in these lectures since Christmas, as an inventory, or if you like a more humble word, a "Zoo" containing all the different forms that facts may have. I should prefer to say "forms of facts" rather than "forms of propositions"... In accordance with the sort of realistic bias that I should put into all study of metaphysics, I should always wish to be engaged in the investigation of some actual fact or set of facts, and it seems to me that this is so in logic just as it is in zoology. In logic you are concerned with the forms of facts, different logical sorts of facts, that there are in the world. (PLA, 191)

Thus logical atomism is a metaphysical view inspired by logical analysis but not a simple projection of the features of language into the world. Instead the analysis of propositions is a guide to an analysis of the facts which correspond with them, an analysis, however, that leads to the discovery of logical categories in the world and the logical atoms that make it up. A survey of the metaphysics of logical atomism should therefore look at parallel developments in Russell's logical doctrines and his metaphysical views.

Some of the views described as logical atomism in the works from 1918 to 1925 are found in the Introduction to the first edition of Prinicpia Mathematica [PM] in 1910 and recur past the appearance of the second edition in 1925. This essay will take the metaphysical and logical views of Russell bounded by the two editions of PM as the 
scope of "logical atomism" and will trace the development of some of them. Despite the move to the doctrine of extensionality with the Second Edition there is a great deal of uniformity of views on logical matters over this period and just a few striking changes in ontology such as the move to neutral monism. According to this periodization one of the most distinctive feature of logical atomism is its account of truth as a correspondence between propositions or their successors which are the objects of logic, and facts, which constitute the world. In his 1924 paper Russell suggests that "realism" also characterises the view but is not central to it and, indeed, that term certainly does not single out the particular views of this period. From the early rejection of the monistic metaphysics of Bradley and the idealists, Russell's view was always realist, seeing the world as composed of many distinct individuals standing in external relations to each other. This realism and atomism in Russell's metaphysics go back to the earliest stages of his rejection of idealism by 1900 , but the limits of a distinctive view properly called "logical atomism" can be settled by the appearance of facts, as clearly distinguished from true propositions, in his ontology from 1910. The many independent objects in the world have properties, that is, exemplify universals, and stand in external relations to each other as constituents of facts, as he calls them, "complexes", which are the real substance of the world.

\section{Propositions}

One obstacle to interpreting the ontology of logical atomism as based on the correspondence between facts and propositions is that at the same time that facts 
feature prominently in Russell's thought, propositions have disappeared as "single entities". This period is marked by his ongoing search for an analysis or "construction" of the seeming unity of propositions. The various solutions are described as the "multiple relation" theory of judgement. To use his standard example, when $x$ judges that $a R b$, there is no binary relation of $x$ to some complex proposition, that $a R b$, which itself will be true or false depending on whether $a$ bears the relation $R$ to $b$. Rather the judgement is a complex relation between $x$ and those constituents $a$, $R$, and $b$, taken individually. Believing is a relation $B$ which holds between the subject $x$ and those constituents, which together constitute the complex fact that $B(x, a, R, b)$, which exists whether or not $a$ is related by $R$ to $b$. Because the number of arguments of $B$ and their logical types can vary as widely as there are objects of belief, this relation $R$ is a multigrade, or "multiple" relation. The suggestion is that all occurrences of propositions will be like those in judgements or beliefs, and so propositions are not single entities at all.

This denial of unity to propositions, however, was not accompanied by any reluctance on Russell's part to use variables for propositions, or to speak of "all propositions" and so to quantify over them, although he does say that such a device will not be necessary for the derivations of Principia (PM, 185). This has suggested to some that the logic of PM is not in keeping with the metaphysics of logical atomism, at least not with the multiple relation theory, and even that a nominalist account of propositions as just sentences was intended. Influenced as analytic philosophers are by Quine's 
doctrines, it is easy to see the referential devices, ultimately the bound variables, as the very expression of the ontological commitment of a theory. How can Russell both deny the existence of propositions and then use variables ' $p$ ' and ' $q$ ' for them? This is especially problematic since symbolic logic is based on the logic of propositions and there should be propositions to be the values of propositional functions which in turn constitute the range of the higher order quantifiers in the logic. One line of interpretation is to argue that Russell must mean all such variables as schematic or stand ins for sentences. On this interpretation ' $p$ ' and ' $q$ ' are not variables that range over propositions as ordinary variables ' $x$ ' and ' $y$ ' range over objects, but really are schematic letters holding the grammatical places of sentences. Quantification over propositional functions, then, is to be interpreted as saying that there is some predicate or expression which, when substituted into what follows, produces a true sentence. This is the "substitutional interpretation" of the quantifiers, by which one treats a first order predication, ' $(\exists x) f(x)$ ', which seemingly directly quantifies over objects, as rather actually true just in case there is some name ' $a$ ', substitutable for ' $x$ ', which yields a true instance ' $f a$ '. A second order sentence, which seemingly quantifies over functions, will be true if some instance is true in which a predicate is substituted for the second order variable ${ }^{1}$. On this account propositions are just sentences, and propositional functions nothing more than predicates. The plausibility of such a

${ }^{1}$ Gödel [1944] suggests this interpretation. See Sainsbury [1980] for details. 
nominalist interpretation of Russell's logic is a central interpretive issue for students of logical atomism and the problem of reconciling the multiple relation theory with the formalism of the logic is only one that leads to it. Whatever the larger issues, it does seem clear that Russell took the multiple relation theory to be compatible with the theory of $\mathrm{PM} .^{2}$ One must conclude, then, that some of the primitive expressions of the language of PM do not stand for ontologically primitive non-linguistic entities. The correlation of basic expressions in the logic with basic items in the ontology is not exact. Still, however, any logical complexity there is in an expression will represent genuine complexity in the fact or entity that it represents.

Russell's worries about propositions, in the form of puzzles about the logical analysis of belief, are a reflection of the central thread in the developments in logical views that frame this period, the move from the first edition of PM to the second. ${ }^{3}$ These developments are almost contemporaneous with Russell's interaction with Ludwig Wittgenstein, which began with Wittgenstein's arrival in Cambridge in 1911 and end

2 The fact that these sections were presented with the rest of the introduction as a single paper "The Theory of Logical Types" (Papers 6, 3-40) before the publication of PM is contrary to the suggestion by Church ([1984], 513) that they are a late addition to the text.

3 The second edition of PM differs, aside from the resetting of all three volumes, just in the addition of a new introduction and of three appendices. The references to the two editions, then, will ordinarily just be to the respective introductions, with reference to the appendices marked. From various indications from Russell and Whitehead it is clear that the introductions were primarily Russell's work, however much collaboration there was in the technical details of the body of the text. I will therefore refer to PM as Russell's work, intending the reference to be taken to the views expressed in the introductions. 
with Russell's frequent acknowledgment of Wittgenstein's influence both in the second edition of PM and in the philosophical writings PLA and LA. The interaction of Russell and Wittgenstein is the subject of another essay in this volume, so here the results for Russell's development will only be touched on in passing.

\section{Extensionality}

The emergence of the doctrine of extensionality is a second development of the atomism period, accompanying Russell's doubts about propositions as unities. In the second edition of $P M$ Russell proposes that functions all be treated extensionally by asserting that coextensive functions (those true of the same individuals) are identical. Thus from $(x)(f x \equiv g x)$ we may infer $f \hat{x}=g \hat{x} \cdot{ }^{4}$ Russell does not interpret this consequence in a semantic way as Quine, does who holds that in extensional logic propositional function variables range over sets, or as Frege does, holding that predicates designate concepts which are extensional in virtue of being functions (from objects to truth values) and that sentences (or rather thoughts) designate truth values.

4 The formulation of the principle of extensionality for higher order propositional functions is a matter of contention and technical complexity. To begin with it must be decided what theory of types is intended for the Second Edition of PM. Allen Hazen has pointed out that in Gödel's [1944] there is a passing suggestion that while functions will be distinguished by level, that is, by the use of quantification in their definition, a given function will take arguments of any level. If to be coextensive is to agree on all arguments, it becomes unclear how this principle could even be stated, and how it could be used, as it requires a seemingly illegitimate generalization over all levels. Without a clear grasp of the system of the Second Edition, it is not possible to assess its main technical content, the derivation in Appendix B of the principle of mathematical induction without using the axiom of reducibility. It clearly does not work if one stays 
Although Russell mentions Frege's view (PM, 401) describing it as the view that there are only two propositions "one true and one false", he rejects it on the grounds that sentences cannot be names. ${ }^{5}$ Truth values do not appear in the metaphysics of logical atomism as individuals or at any level in the hierarchy of types. Propositions do not appear officially either, of course, but in so far as they do appear, they would be of a different logical type than the objects to which Frege assimilates classes and truth values. Russell continues to speak of propositional functions as the basis of logic throughout this period and the no-class theory that defines classes with propositional functions is still maintained.

If the doctrine of extensionality does not amount to the thesis that functions designate extensions, what ontological content does it have? The key to understanding Russell's interpretation of extensionality comes from recalling that the identity symbol, ' $=$ " , is a defined symbol in PM. Russell adopts Leibniz' doctrine of the Identity of Indiscernibles as his definition of identity at PM $* 13.01$. Objects $x$ and $y$ are identical just in case any ("predicative") function $f$ which is true of $x$ is also true of $y$. The same applies to all logical types. To say that $f \hat{x}=g \hat{x}$ is to say that any second order function true of $f \hat{x}$ will also hold of $g \hat{x}$ and vice versa. But what sort of second order

with the system of the First Edition. Myhill [1974] gives the technical details.

5 He repeats this in PLA. Propositions can only be asserted, they cannot be named, as a consequence of their logical type. Only individuals at the bottom of the type hierarchy can be named. 
functions hold of first order functions? Here we find a role for one of the two slogans that Russell uses frequently to characterize extensionality, the thesis that a function "can only enter into a proposition through its values" (PM2, xxix). This would appear to be the claim that a propositional function will only contribute its values, which are propositions, to those contexts in which it occurs. In other words, functions yielding the same values for the same arguments will differ in their properties. If the values of the functions are finely individuated intensional propositions, however, the logic will still not be extensional. The decisive second characterization of extensionality is that propositions may only appear in truth-functional contexts. Officially the only primitive sentential connective in the language of the Second Edition is to be the Sheffer stroke ' $p / q$ ', the truth functional connective with the same values as 'not both $p$ and $q$, true if one or both of $p$ and $q$ are false, false otherwise. All functions of propositions must be derived from this one connective. Putting the two slogans together, then, if propositional functions $f \hat{x}$ and $g \hat{x}$ are coextensive and also only contribute the truth values of the propositions that are their values to higher order contexts, their intensional aspects will make no difference and as indistinguishable they will be considered identical.

Russell did not think that adopting the doctrine of extensionality required him to abandon the notions of propositional function and proposition in favour of extension and truth value. Rather he held that logic of PM did not have the resources to distinguish functions that were coextensive, or distinguish propositions with the same 
truth values. Indeed, Russell takes the consequence that class expressions ' $\hat{x}(f x)^{`}$ and the expressions for propositional functions, ' $f \hat{x}$ ', have the same "meanings" and so there is "no longer any reason to distinguish between functions and classes"(PM2, xxxix). But that doesn't mean that he adopts an ontology of classes. Rather, he goes on to say that this shows that it is classes that have lost even that "shadowy being that they retain in $* 20 "$. In other words functions are retained in the logic and talk about classes is successfully eliminated because of the extensional nature of the logic.

\section{Nominalism}

Several different features of the metaphysics and logic of Logical Atomism conspire to suggest that Russell abandoned an earlier platonism about universals, such as is explicitly described in Problems of Philosophy [POP], and adopted nominalism, identifying propositional functions and universals with predicates in the language of PM. These are distinct from the troubles with the multiple relation theory discussed above and mostly arise after the first edition of PM. Both Gödel [1944] and Cocchiarella [1987] describe Russell's later ontology as nominalist in this way and this does fit with Russell's own later description of his view as seeing logic as more linguistic than he originally thought (MPD). Yet even that work includes a defence of the existence of universals, as he reminds us of the restaurateur who insists on calling horseflesh "beef”(MPD, 162). Something, he says, keeps it horseflesh, whatever it is called. An analysis of these issues will show that the purported move to nominalism is not as obvious as is suggested. 
One of these developments that suggests a move toward nominalism is Russell's adoption of Wittgenstein's notion that atomic facts only involve lowest level properties and individuals. In the Introduction to the Second Edition of PM, atomic propositions are are identified as of the forms:

$$
R_{1}(x), \quad R 2(x, y), \quad R 3(x, y, z), \ldots
$$

Russell then says that "terms that occur as the $R$ 's occur are called 'universals'..." whereas the terms that occur in any of these expressions as the values of the variables $x, y$, etc, are "individuals" or "particulars"(PM2, xix). There are no atomic sentences where the universals $R_{1}, R_{2}, \ldots$ in turn appear as subjects, and so, presumably, all atomic facts are composed only of individuals and (first order) universals. There will be expressions in the language that include higher order quantifiers, quantifiers ranging over functions, for some notions are defined by generalising with respect to first order predicates. How are these higher order formulas to be interpreted? Russell says that "there is no logical matrix of the form $f(\phi ! \hat{z})$ " (PM2, xxxi) and that any such purported matrix will be definable as some stroke function of atomic, first order sentences. A common assumption is that he intends to treat these defined higher order matrices as merely linguistic, as simply predicates, and not as symbols for some other entity. Indeed later Russell is at pains to prove that any formulas with higher order quantifiers will be replaceable with first order equivalents. He considers a purported example, saying that the seemingly atomic sentence " 'before' is a relation" should be analysed as "If I assert that $x$ is before $y, \mathrm{I}$ assert a relation between $x$ and $y$."(PLA, 
182). Higher order predications, it would seem, are really "logical constructions" so they are linguistic only if logical constructions must be seen as part of some nominalistic project. What's more, nothing is implied by this paraphrase about whether the first order predicate 'before' stands for a universal. This evidence is inconclusive, at best showing that Russell became suspicious of primitive higher order functions.

Because logic seemingly demands no more higher order entities than can be defined it is possible to give a linguistic interpretation of the system, treating the higher order quantifiers as "substitutional". The mere existence of a substitutional interpretation, however, does not show that the intended interpretation of the quanitifiers is substitutional. Again, the evidence for a nominalist treatment of functions is not strong.

There are other indications of some move towards seeing logic as linguistic. We find, for example, “A proposition is just a symbol.”(PLA, 166) and

To understand 'red', for instance, is to understand what is meant by saying that a thing is red. You have to bring in the form of a proposition. (PLA, 182)

and

The theory of types is really a theory of symbols, not of things. (PLA, 232) 
These look like explicit statements of nominalism, but a closer examination is necessary. Symbols for Russell are what we would call interpreted symbols, symbols with their meaning. ${ }^{6}$ Russell is happy to identify a sentence as object as some collection of marks on a page or vibrations in the air. It is words with their meanings that become more substantial. Within the theory of types words as mere symbols may be individuals, of the lowest types. Their meanings, however, will produce relations between them and entities of differing types. Thus:

...the relation of the symbol to what it means is different in different types. I am not now talking about this hierarchy of classes and so on, but the relation of a predicate to what it means is different from the relation of a name to what it means. There is not one single concept of 'meaning' as one ordinarily thinks there is, so that you can say in a uniform sense 'all symbols have meaning', but there are infinite numbers of different ways of meaning, ie. different sorts of relation of the symbol to the symbolised, which are absolutely distinct. (PLA, 233)

A nominalist should hold that there is just one kind of entity in the world, concrete particulars, which include both names and the individuals they name. Singular terms and predicates or "general terms" differ only in the relations they bear to individuals,

\footnotetext{
6"'When I speak of a symbol I simply mean something that 'means' something else, and as to what I mean by 'meaning' I am not prepared to tell you" (PLA, 167). He goes on to say that an account of meaning will involve a strictly infinite number of different things including cognitive relations like knowing. This seems
} 
where those relations are of the same logical type, they relate particulars to particulars but may differ in the number of entities they relate. A nominalist should see a general term as one that "names" (as suggested by the etymology of "nominalism") or "applies to" many individuals, while a singular term names only one. This is not Russell's notion of meaning. The theory of logical types may be a theory of symbols, but it is more importantly a theory of the meanings of those symbols seen as entities which come in different logical types. There is something essentially predicative about 'red' but that has to do with its logical type, a type higher than that of individuals. That is what is required to understand 'red', not knowing something about the symbol 'red' as a concrete particular.

\section{Facts}

The logical notion of extensionality manifests itself on the ontological side as a view about the nature of complex facts, in particular, judgements or beliefs. The issue is over what sort of fact corresponds with propositions reporting beliefs or judgements. At the time of PM Russell seems to allow facts involving other facts as constituents. Thus perception is seen as a case where we are directly related to a fact. "The complex object 'a-in-the-relation-R-to-b' may be capable of being perceived; when perceived it is perceived as one object"(PM, 43). Belief, and judgement, however, are quite different, for they do not directly relate us to facts. We can make a judgement that is 
false or believe a proposition that does not obtain. Russell did not want to analyse propositions about belief and judgement as relations to propositions and so had to find some other analysis. His response was the "multiple relation theory" of judgement mentioned above. Ontologically, it arises out of Russell's rejection of propositions as the objects of propositional attitudes such as belief and judgement. Russell's attention is directed to what sort of facts there might be that would seem to involve at least two different "verbs", as the sample belief of $x$ that $a R b$ analysed as $B(x, a, R, b)$ above seems to involve both $B$ and $R$. A contemporary discussion of these issues would probably focus on an attempt to find a suitable construction of propositions, so as to avoid them in some sense, but keep the analysis of belief and the like as relations between and individual and a proposition. What seems to logicians now to be an investigation into non-truthfunctional connectives Russell always couched in terms of the nature of facts.

Throughout the period of atomism Russell struggles with the nature of propositions with "two verbs" wondering how they could be given spatial representation in notation (in TK and PLA, for instance), or replaced by facts about other things, as in PM. Russell seems to have found both the original problems with the theory in Wittgenstein's criticisms of his "multiple relation theory" and the ultimate resolution in Wittgenstein's own picture theory of representation in the Tractatus Logico- 
Philosophicus [1922]. ${ }^{7}$ In his introduction to the Tractatus (and again in the Introduction and Appendix C to PM2), Russell presents Wittgenstein's proposal that the occurrence of a belief or other mental representation is itself an atomic fact. Just as a sentence is a string of symbols in a certain order, a belief will be composed of some complex of representing mental items. In the example above, $x$ 's thoughts will include a series of mental items, one representing $a$, another $R$, and another $b$, all arranged in a way characteristic of the occurrence of items when $x$ is judging that the second applies to the first and third, in that order. This is a reduction of the intensional relation of belief to individual representation relations for mental names and a mode of combination in a mental representative medium, the "language of thought". Russell himself does not seem to see this as a first step in an analysis or elimination of the whole phenomenon of intensionality, but rather a solution to his problem of the combinations of facts in the world. No fact can be included in another, all facts are "atomic" in the sense of only including a relation and one or more individuals that it "relates".

7 See Griffin [1985] for the history of difficulties for the multiple relation theory, and Wittgenstein's role in it. The difficulties centered around the "order problem", how it is that statements of judgements are only well formed if a well formed proposition is judged, while the multiple relation account seems to allow almost any sequence of objects of various types to be related by the judging relation. What is to keep us from allowing a judgement that "The table penholders the book" or similar nonsense? 
Although Russell agrees with Wittgenstein on the issue of extensionality and the resulting view that facts do not occur "within" each other but are combined solely by truth functions, he does not seem to have come to agree with Wittgenstein about the need for general facts. (General facts appear in the PLA lectures but are not mentioned again in the 1924 paper.) Russell is concerned that any collection of atomic facts, say that $a$ is $F, b$ is $F, c$ is $F$, etc, will not imply that everything is $F$ unless it is known that $a, b, c$, etc., are all the individuals. Thus there is a fact that corresponds with a general proposition which is not just conjunction of atomic facts about its instances. In the Tractatus Wittgenstein holds that a proper language will "show" that the inference from all instances of the form ' $F(t)$ ' to ' $(x) F x$ ' is valid, as the language will show that those are all the names there are and all objects will be named. Russell, however, did not accept Wittgenstein's notion of "showing" versus "saying", suggesting in the Introduction to the Tractatus (Papers 9, 111) that what Wittgenstein thought could only be shown could in fact be said in a language of a higher type.

Negative facts figure prominently in PLA and are a striking addition to the ontology. Russell claims to have almost started a "riot" at Harvard when he discussed them there in 1914. However attention grabbing they may be, negative facts are no more mysterious than general facts. A negative fact is simply a fact that corresponds with a true negated atomic sentence, eg. $\sim F a .^{8}$ There will be something in the world that

\footnotetext{
8 Recent discussions of "truth makers", that is, of what "makes" a proposition true, sometimes distinguish
} 
makes that proposition true, just as there are general facts that make universal propositions true. Russell balks at disjunctive and conjunctive facts. A disjunctive fact would be one to make $F a$ v $G b$ true which is none the less distinct from the one (or both) of the facts making true the constituent propositions $F a$ and $G b$. Wittgenstein also sees such extra facts as not necessary. The truth of a truth functional compound such as a disjunction or conjunction is determined by the truth value of the atomic propositions into which it can be analysed. Similarly Wittgenstein holds that the mere failing of the fact of $a$ being $F$ to obtain is enough to account for the falsity of $F a$.. On this semantic conception negation and conjunction are defined in terms of their effects on the truth values of compound sentences, rather than some distinctive correlate in facts. Facts are then only needed to account for the truth or falsity of atomic sentences. Apparently Russell did not come over to Wittgenstein's view on this issue, as negative facts appear after the PLA lectures in AMi from 1921 (AMi, 276). This leaves him at the end of this period then with an ontology of atomic, negative and general facts.

\section{Analysis and Atoms}

Russell describes his philosophical method as "analysis" and of a piece with his rejection of Idealism. He repeatedly denied that analysis leads to "falsification" as the monists claimed. Individuals which have been isolated by analysis can be known accurately without having to acknowledge all the other objects to which they might

between what makes a negative sentence $\sim F a$ true and what makes the negated $F a$ false. Russell, however, 
bear relations of different sorts. While clearly based on analysis, however, logical atomism makes suprisingly little use of the of the idea of a "atom". The project of analysis has metaphysical, logical and epistemological aspects, leading to what W. Lycan has distinguished as three corresponding notions of the end product of analysis, the atom (Lycan [1981]). We may look for a use for "atoms" in each of these three aspects of the philosophy.

Russell's metaphysical alternative to Monism with its single substance, the Absolute, is a world involving many independent and externally related individuals. Analysis will reveal the constituents of facts or complexes that make up that world and if there are ultimate constituents those will be what we may call "ontological atoms" (following Lycan). In PLA Russell suggests that his project does not require that there be any such ultimate constituents. It might be that the analysis would never halt, yet it would be no less correct as a method for that. This notion of an "atom" as an ultimate constituent of a fact contrasts with others in use in metaphysics. Atoms are always "simple" in some way, but proposals as to what dimension of complexity is to be considered varies. Some hold that it is with respect to parts, thus an atom has no spatial parts. Russell seems to rely on the relation of an object to a complex or fact of which it is a constituent. Indeed he speaks of facts as "complexes" (as in the quote above from PM) it would seem not only because they have constituents and so are complex, but also, one might argue, because they are 
the only sort of complex entities that there are. ${ }^{9}$ Russell does not consider complexes to be "mereological sums" or just wholes of which the constituents are parts, as the part whole relation is not a simple relation between individuals as it was later for mereology, but rather a logical relation like that of predication. ${ }^{10}$ Simple substances are also often held to be independent in some sense, not relying for their existence or nature on other objects. Russell is silent about contingent existence and modal issues in general, and concentrates rather on the notion of "nature" for discussions of substance. The doctrine of external relations, which Russell and Moore championed from early on, holds that objects can stand in genuinely external relations, which are not reflected in the natures of their relata. Thus metaphysical atoms would be things that stand in relations without those relations being part of their natures. Since it is in the nature of a whole to contain its parts, atoms will have to be simple, that is without parts. Russell does seem clearly to be committed to the notion of atoms in this metaphysical sense, even if it may turn out that there are none, as analysis can continue indefinitely.

Russell sometimes characterises monism in an epistemological rather than metaphysical way. In this form monism becomes the doctrine that one cannot know an object without knowing all of its relata, and to know those adequately in turn will ultimately require knowing about everything. To parallel his metaphysical atomism,

9 Thus "I mean by a fact anything complex", from 1919, (Papers 8, 278).

10 See the discussion in Principles of Mathematics, chapt. XVI. 
Russell would have an epistemological atomism. It is possible to "know" objects adequately without knowing their relations to other objects. Indeed this form of knowledge is not necessarily based on the features of an object at all it can be known simply by direct "acquaintance", without being known somehow indirectly through its qualities at all. There is no simple notion of "epistemological atom" for this epistemological atomism, to go along with metaphysical atoms. It is not correct to say that objects of acquaintance are atoms, for Russell suggests that it is possible to be acquainted with a complex object, say our total perceptual experience at a moment, without having analysed it into atoms. Thus:

"We may be acquainted with a complex without being able to discover, by any introspective effort, that we are acquainted with the objects that are in fact its constituents".(TK, 121)

A complex sense datum, say of a red patch next to a blue patch, would not be an atom, but could, seemingly, be an object of acquaintance. Upon analysis, however, that complex will be seen as a fact, the red patch's standing next to the blue patch, and so be analysed into its constituents, themselves possibly atomic. Sense data in general are not atomic, as they can have duration and seemingly have parts as well.

The notion of atom does not fit clearly into Russell's epistemology of experience any better than its metaphysics. One important epistemological role for analysis does not seem to rely on a notion of atom at all. Russell describes that process of finding axioms for mathematics, and the subsequent derivation of them from logic as a 
process of analysis. In this process the results of analysis, the axioms, do not have the usual role of epistemic primitives. The consequences of the axioms, say that $1+1=2$, may be much more certain than the axioms, the principles of classes and the logic on which they are based. Russell proposes that axioms be accepted if they allow us to derive all the consequences that we seek in a simple and systematic fashion. Analysis thus can result in knowledge of truths having a certain epistemic priority, but that priority is not one of certainty. They are rather prior in the order of justification where justification is a matter of systematic derivation, not a process which passes on some of the certainty of axioms to their consequences.

The notion of a logical atom is the most straightforward of the three. Logical analysis produces atomic propositions as an ultimate product, propositions that correspond directly with atomic facts. Each atomic proposition asserts the holding of a relation among one or more particulars. Logically proper names will stand for objects of acquaintance. Logical atoms, then will be propositions that are atomic with respect to logical analysis. It is, of course, a characteristic thesis of logical atomism as a metaphysical doctrine that the logical analysis and metaphysical analysis coincide, that the atoms for one are the atoms for the other and that the logical analysis of facts constitutes some sort of metaphysical analysis. If there is no end to metaphysical analysis, and thus no metaphysical atoms, nothing we use can be a genuinely atomic proposition. Propositions seemingly applying an atomic predicate to some names will 
be liable to further logical analysis either analysis of the predicate or the replacement of some of the names by definite descriptions.

That a proposition is not genuinely or ultimately atomic, however, does mean that its analysis as atomic is not adequate for logical purposes. A sentence may be treated as atomic for logical purposes even though it is subject to further analysis. Consider the case of definite descriptions. It is an important part of Russell's account of descriptions that while descriptions may look like singular terms in the surface or apparent syntax of sentences they must be distinguished in ultimate logical form. Still, however, a result in logic of the theory of descriptions is that descriptions such as "the $F$ ", when proper (when there is exactly one $F$ ), and in extensional contexts, in fact obey the logical principles governing names. This is the purpose of section *14 of PM devoted to descriptions. Since functions such as "the successor of $n$ " will be defined using relations as "the entity $m$ such that $m$ is the successor of $n$ " it is necessary to prove that function expressions (provided they are well defined) will obey the logic of singular terms. Thus in fact the theorems of $* 14$ show that if proper, coreferential descriptions can be substituted for each other, and in general are subject to the basic logical laws. As a result a sentence with a description, say "the $F$ is $G$ ", can be treated as analogous to a genuinely atomic sentence " $a$ is $G$ ", provided that the description is proper. There is thus no need to determine whether a given sentence is genuinely atomic in order to determine its logical properties as long as the singular terms in it are seen to be well defined, that is, denote a unique object. The application of logic to 
sentences thus does not require that they be completely analysed into logically atomic sentences. Logical atomism and its method of logical analysis does not require the existence of logical atoms!

These unsuccessful searches for atoms suggest that one should regard the "atomism" in "logical atomism" as just expressing a commitment to analysis as a method, and perhaps also as expressing the central role of atomic sentences in logic, rather than as some more substantive view about the end results or products of analysis. ${ }^{11}$

\section{Logical Construction}

Many of these issues over various notions of analysis and the products of the process can be resolved by examining the complementary process of logical construction. In LA Russell attributes the method to Whitehead, but from the examples he gives it is clear that it is a thread running through the whole of his own philosophy. In a famous bon mot Russell describes construction by contrasting it with the method of hypotheses:

The method of "postulating" what we want has many advantages; they are the same as the advantages of theft over honest toil. Let us leave them to others and proceed with our honest toil. (IMP, 71)

The honest toil is that of logical construction, the method of hypotheses is that of adopting axioms to describe purported entities. The best model of construction is 
Russell's original project of constructing numbers from classes of equinumerous classes. Here the method of postulating would be to rest content with Peano's Axioms thus making all claims about numbers hypothetical with the axioms as hypothesis. Rather the work is to construct the numbers, in Russell's case to treat numbers as classes of equinumerous classes, in such a way that the theory of numbers including Peano's "Axioms" could in fact be derived as theorems.

In LA Russell lists other examples of the method of construction, starting with the method of "abstraction", of "substituting equivalence classes for a common quality, eg. a shared magnitude". Another example is the elimination of classes "as single entities" in $\mathrm{PM}^{*} 20$, the "no-class" theory of classes. Then Russell includes the theory of definite descriptions, and mathematical examples such as the construction of series, ordinal numbers and real numbers. Finally there are the examples of the construction of points and instants as sets of events, and the construction of matter from events. It is the construction of matter from events of experience, the project that Russell describes as "neutral monism" that is one of the most striking doctrines of the logical atomism period. The construction of matter from sense data and the theory of definite descriptions are often taken as models of Russell's method, and taken as such suggest the prevailing view of the ontological import of logical construction that can be challenged. That view, defended by M. Sainsbury [1980], is that the project of

${ }^{11}$ Russell discusses the possiblity that analysis does not end in his reply to Urmson in MPD, chpt. XIII. 
construction is to replace purported entities with classes of other objects, ultimately of sense data. Those classes are then eliminated via the "no-class" theory in favour of propositional functions. Functions, in turn, are subject to the nominalist interpretation discussed above, and quantification over them disarmed of ontological import by being given a substitutional interpretation. The upshot is that logical construction is the first step in a nominalist ontological program of "elimination" of purported entities in favour of linguistic items and sense data. This interpretation of the program may be challenged, however.

Russell's discussions of logical constructions do indeed center on the issue of avoiding ontological commitment:

One very important heuristic maxim which Dr. Whitehead and I found, by experience, to be applicable to mathematical logic, and have since applied to various other fields, is a form of Ockham's razor. When some set of supposed entities has neat logical properties, it turns out, in a great many instances, that the supposed entities can be replaced by purely logical structures composed of entities which have not such neat properties. In that case, in interpreting a body of propositions hitherto believed to be about the supposed entities, we can substitute the logical structures without altering any of the detail of the body of propositions in question. This is an economy, because entities with neat logical properties are always inferred, and if the propositions in which they occur can be interpreted without making this inference, the ground for the inference fails, and our body of propositions is secured against the need of a doubtful step. The principle may be stated in the form: "Whenever possible, substitute 
constructions out of known entities for inferences to unknown entities." (LA, 164)

The grounds for adopting a construction does not seem to be ontological parsimony for its own sake. The reduction in ontology has the effect of reducing the number of assumed propositions that are needed in order to derive the "neat" properties of the objects, those features that have a logical character to them. It is a parsimony of theory, allowing what would otherwise have to be assumed as axioms to rather be proved as theorems using the definitions supplied by logical constructions. This is a general feature of all the constructions. Consider, for example, the instance of the theory of descriptions. While specifically aimed at replacing Russell's own prior theory of denoting concepts, and perhaps generally motivated by the desire to avoid Meinong's commitment to the likes of the Golden Mountain, the concrete project of the theory is to allow the derivation in PM of a number of theorems using definite descriptions as discussed above. Indeed, examination of Russell's objections to Meinong's theory shows that they concentrate on seemingly inconsistent consequences that can be derived from the postulates of object theory, rather than a simple objection to unnecessary entities. ${ }^{12}$ Thus, for example, Meinong's use of an unrestricted principle that "the $F$ is $F$ " leads to the proof that "the existent round square exists". Russell's theory of descriptions provides a refined theory. His analogue of this principle is that one must first establish that the desciption "the $F$ " is 
proper, essentially proving that there is exactly one $F$ first. The objection to Meinong's theory was more that it lead to the wrong theorems as much as that it postulated unnecessary entities. Likewise the no-class theory clearly is intended to allow the derivation of the features of classes as theorems, rather having to hypothesize them with axioms.

The same even applies to the treatment of matter. Russell describes certain "neat" features of matter, for example that no two physical objects can be in the same place at the same time, as having a logical flavour to them. If physical objects and spatial relations are "constructed" from sense data, it will be possible to derive such "neat" features of physical geometry from logic alone. It isn't obvious then that Russell's position should be described as the view that physical objects simply are classes of mental sense data, thus as a genuine phenomenalism. That Russell might have ended this period as such a phenomenalist would be an ironic development for the Realist philosopher who began his career criticising idealism with its ontology of ideas rather than matter. ${ }^{13}$. At the time of his POP Russell saw matter as something inferred as the source of our sensations, known by description as "the cause of such and such sense data". In the passage cited above he might seem to say that under Whitehead's

12 In “On Denoting” from 1905, and his reviews of Meinong all reprinted in Lackey [1974].

13 See Alberto Coffa ([1991], 87, 93) who describes the theory of sense data as "reified psychologism, suggesting that they amount to a relapse into idealism. Russell's "neutral monism", however, makes sense data less clearly in the idealist tradition. 
influence he has come to replace inferred matter with constructions. Although Russell does talk about the matter as constructed of sense data, this seems to be only relative to certain purposes, in particular the derivation "neat" features of matter that look too much like logical features to be inductive generalisations. The positive project of finding the definitions ensures the derivation of "neat" features that constitutes the program of logical construction. Attention to these definitions will explain some of the problematic features of analysis mentioned above. The goal of analysis is to find the appropriate objects and definitions with which to carry out the program of construction. These may not coincide with what is intuitively certain or simple. Indeed it is not clear that the resulting construction has any claim to being a "reduction" of ordinary objects and notions. Russell says that a construction will serve all the "scientific purposes that anyone can desire" (PLA, 236). Those scientific purposes, however, do not seem to be those of current scientific realism which proposes that we take as genuinely real just those entities postulated by our best scientific theories. Rather than trying to give an account of what ordinary objects really are, Russell is proposing a substitute that will allow certain derivations in logic of truths that seem logical in character. Logical construction may not be a construction of our world, but rather of a replacement that serves certain theoretical purposes.

This indeed seems to be how Russell's project of construction was perceived by Carnap, whose later Logical Structure of the World ([1928]) abandons claims to ontological truth in favour of extensional isomorphism between the world and its 
construction. The project of construction, so conceived, continued in the project of producing set theoretic "models" of various theories and entities. A set theoretic construction of time or space is not intended as a theory of what those things really are, but rather of a structure which shares structural features with the object studied, those structural features being derivable from the constructing definitions. With the development of logic it became clear that it was trivial to find some set theoretic construction to provide entities for any consistent theory. The issue then became how to find from those various models one that was "intended" or real, one that was a genuine model of the world rather than an artificial construction. Perhaps for this reason the project of logical construction withered, despite Carnap's early contribution to it.

Logical atomism played an important role as a foil for succeeding analytic philosophy. Both Wittgenstein's early views in the Tractatus and his subsequent turn from those views were directed at Russell. As J.O.Urmson details in his [1956] the logical positivists and later ordinary language philosophers used criticisms of the language and ontology of atomism as a starting point for their own positions. Logical positivists retained the central role for the symbolic logic but, using the verifiability criterion of meaning, abandoned the sort of metaphysical considerations that are central to atomism. Urmson argues that even before the post World War II flowering of ordinary language philosophy, criticisms of atomism had focussed on the commitment to extensionality and associated independence of atomic facts, the picturing account of 
truth and correspondence, and the phenomenalist reading of the project that came from emphasizing the nature of sense data and phenomena as the basic objects. The characteristic issues of post war analytic philosophy can be seen as arising from criticisms of atomism, including the criticism of logic as "ideal language", the attack on sense data and their connection with a foundationalist epistemology based on acquaintance and the very idea of drawing realist ontological conclusions from the use of language. One cannot read classics of later linguistic philosophers such as Wittgenstein (1953), Austin (1962) or Strawson (1959) without keeping Russell's logical atomism clearly in mind. 
Bibliography

Austin, J. L., Sense and Sensibilia., Oxford:Clarendon Press. 1962.

Carnap, Rudolf, The Logical Structure of the World \& Pseudoproblems in Philosophy, tr. by R.A.George. [2 $2^{\text {nd }}$ ed.] London, Routledge \& K.Paul, 1967. Originally published 1928.

Cocchiarella, Nino B. "Russell's Theory of Logical Types and the Atomistic Hierarchy of Sentences", in Logical Studies in Early Analytic Philosophy (Columbus: Ohio State University Press) 1987, 193-221.

Coffa, J. Alberto, The Semantic Tradition from Kant to Carnap: To the Vienna Station, Linda Wessels, ed., (Cambridge: Cambridge University Press), 1991.

Church, Alonzo, "Russell's Theory of the Identity of Propositions", Philosophia Naturalis 21, 1984, 513- 522 . 
Gödel Kurt, "Russell's Mathematical Logic" in The Philosophy of Bertrand Russell, P.A. Schilpp, ed., The Library of Living Philosophers (Evanston: Northwestern University) 1944, 125-53, reprinted with an addendum in Philosophy of Mathematics: Selected Readings, second edition, P.Benacerraf and H.Putnam, eds. (Cambridge, Cambridge University Press) 1983, 447-469.

Griffin, Nicholas, "Russell's Multiple Relation Theory of Judgement", Philosophical Studies, 47, March 1985, 213-248.

Lackey, Douglas, ed., Essays in Analysis by Bertrand Russell, New York: George Baziller, 1973.

Lycan, William, "Logical Atomism and Ontological Atoms", Synthese 46 (1981) 207229.

Myhill, John, "The Undefinability of the Set of Natural Numbers in the Ramified Principia", in G. Nakhnikian, ed., Bertrand Russell's Philosophy, New York: Harper and Row, 1974.

[POM] Russell, Bertrand, Principles of Mathematics, New York: w.W.Norton, 1903, $2^{\text {nd }}$ ed. 1928.

[POP] Russell, Bertrand, The Problems of Philosophy, Oxford: Oxford University Press, 1912, reprint 1967.

[PLA] Russell, Bertrand, "The Philosophy of Logical Atomism", in The Philosophy of Logical Atomism and Other Essays, 1914-1919, The Collected Papers of Bertrand Russell 8, John G. Slater, ed., (London: George Allen \& Unwin) 1986, 155-244.

[IMP] Russell, Bertrand, Introduction to Mathematical Philosophy, first ed. 1919, reprinted (London: Routledge )1993.

[AMi] Russell, Bertrand, The Analysis of Mind, London: George Allen \& Unwin, 1921. 
[LA] Russell, Bertrand, "Logical Atomism", 1924, in Essays on Language Mind and Matter 1919-1926, Collected Papers of Bertrand Russell 9, John G. Slater, ed. (London: Unwin Hyman) 1988, 160-179.

[LK] Russell, Bertrand, Logic and Knowledge: Essays 1901-1950, Robert Marsh, ed. London: George Allen and Unwin, 1956.

[MPD] Russell, Bertrand, My Philosophical Development, (London: George Allen \& Unwin) 1959.

[TK] The Collected Papers of Bertrand Russell, Vol.7, Theory of Knowledge ed. J. Slater, London: Routledge 1984.

[Papers 6] The Collected Papers of Bertrand Russell, Vol.6, Logical and Philosophical Papers: 1909-1913, ed. J. Slater, London: Routledge 1992.

Sainsbury, R.M., "Russell on Constructions and Fictions”, Theoria 46, 1980, 19-36.

Strawson, P.F., Individuals, London: Methuen \& Co., 1959.

Urmson, J.O., Philosophical Analysis: Its Development Between the Two World Wars, Oxford: Clarendon Press, 1956.

[PM] Whitehead, A.N. and Russell, B., Principia Mathematica , (Cambridge: Cambridge University Press), 1910-13, $2^{\text {nd }}$ ed. 1925-27. (The Introduction to the first edition, pp. 1-84 is [PM1] and the Introduction to the Second Edition, pp. i-xlvi and appendices A,B and C, constitute [PM2]).

Wittgenstein, Ludwig, Tractaus Logico-Philosophicus, trans. C.K.Ogden, London: Routledge \& Kegan Paul, 1922.

Wittgenstein, Ludwig, Philosophical Investigations, London: Macmillan, 1953. 
